\title{
CHALLENGES IN HIGHER ONLINE EDUCATION: DISCOURAGING FRAUDULENT ATTEMPTS ON ONLINE EXAMS
}

Original scientific paper

UDK: 37.018.43:004]:174

JEL classification: A22, 121, 129, M20

DOI: $10.17818 / \mathrm{DIEM} / 2022 / 1.2$

Accepted for publishing: July 8, 2021

\begin{abstract}
It has been more than a year since the coronavirus pandemic pushed higher education even more towards an online format, along with many of its key-activities involved. When it comes to transitioning from conventional face-to-face examination to fully online assessment, the use of e-learning tools such as Moodle may bring multiple benefits but they could also raise a lot of concerns. One of the main concerns refers to content leakage, which involves the unauthorized distribution of the exam subjects, such as question banks, or sharing the quiz attempts with colleagues. When this happens, it can hinder the integrity of the online exams and their unique content, and of course, it will impact grades. There could be various causes for content leaks, such as lack of supervision or maybe settings incorrectly applied to quizzes. However, these could be some of the contributing factors that are enabling students to cheat. In light of the above, the aim of this paper is straightforward: to identify and outline the most important and feasible key-measures that could be adopted in order to detect and prevent or (at least substantially) decrease cheating during online exams. As we will further see, the real challenge appears when it comes to tracking down and grasping cheat scenarios. Fortunately, in this approach, we can mix the facilities provided by technologies used in online classes.
\end{abstract}

Keywords: Moodle, exam cheating, e-learning

\section{INTRODUCTION}

Millions of students around the world are having their education disrupted by the coronavirus pandemic (UNESCO, 2021). Learners and teachers haven't faced this level of disruption in generations, but unlike any time in the past, they find out the ability to continue the process of education even if it can't happen in person. In this uncertain environment, empowered by the distinctive rise of e-learning, education has changed dramatically, and most of its involved keyactivities are undertaken remotely and on digital platforms. 
When it comes to transitioning from conventional face-to-face examination to fully online assessment, the use of e-learning tools such as Moodle may bring multiple benefits but this could also raise a lot of concerns. One of the main concerns refers to academic dishonesty, which involves the unauthorized distribution of the exam content, such as question banks, or sharing quiz attempts with classmates or with a friend who is more knowledgeable to take the test on behalf of a certain student. When this happens, it can hinder the integrity of the online exams and their unique content, and of course, it will impact grades. There could be various causes for content leaks, such as lack of supervision or maybe settings incorrectly applied to quizzes. However, these could be some of the contributing factors that are enabling students to cheat.

It is not new that academic dishonesty among students is a pressing issue in universities (Baran et al., 2020), especially now, when many classes and exams are conducted exclusively online. It should not be surprising that, under these circumstances, cheating occurs and is on the rise. After all, students, consciously or not, tend to cheat because this is somehow endemic, at the root of human nature (Stephens, 2016). It's like a subliminal strategy used to solve problems in day to day life.

Students from contemporary society, driven by their struggle for better jobs, higher wages, self-fulfilment (and, of course, financial self-sufficiency) after graduation, often believe that their dreams will come true not just by acquiring a degree, but also by getting exceptional grades throughout their college career (Choi, 2009; McCabe et al., 2017). This pursuit of the highest possible grades challenges students even more, and also puts them under pressure. (McCabe et al., 2006). Therefore, some of them are more tempted than ever to cheat on exams, especially if they are taken in a favourable environment, i.e. online.

Some studies have identified a strong relationship between academic dishonesty and the economic, cultural and societal value-related background (Orosz et al., 2018; Teixeira et al., 2010). For instance, some findings pointed out that there is a link between cultural values such as collaborative groups and collaborative academic cheating. The figures place Romania among the countries where cheating on exams is a common practice $(71.8 \%)$, while the overall countries average is $58.2 \%$ (see Figure 1). Other studies (Bucciol et al., 2020) outlines that the probability of cheating is lower for students from Scandinavia, North America and the UK, when compared with students from East and South Europe, who seems to have a higher cheating tendency (see Figure 2). 


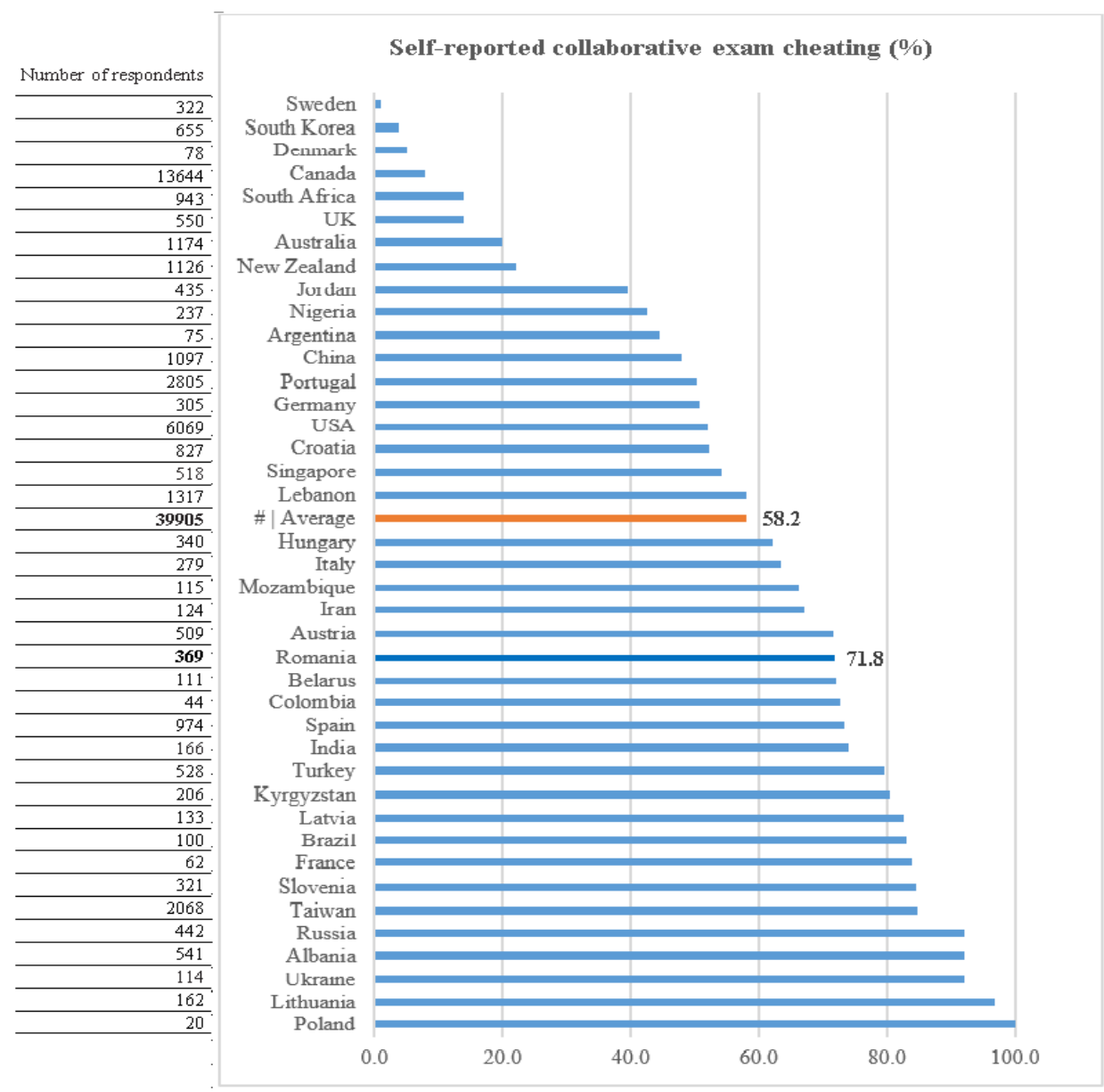

Notes: Questions: 'Have you ever copied on test or exam?' and 'Have you been asked to help a classmate cheat on exam?' /Answers: 'Never' =0, other frequency measures (e.g. 'Yes', 'Maybe') $=1$

Source: own processing, based on (Orosz et al., 2018; Teixeira et al., 2010)

Figure 1 Graphic representation of 'Self-reported collaborative exam cheating' data, collected from 40 countries.

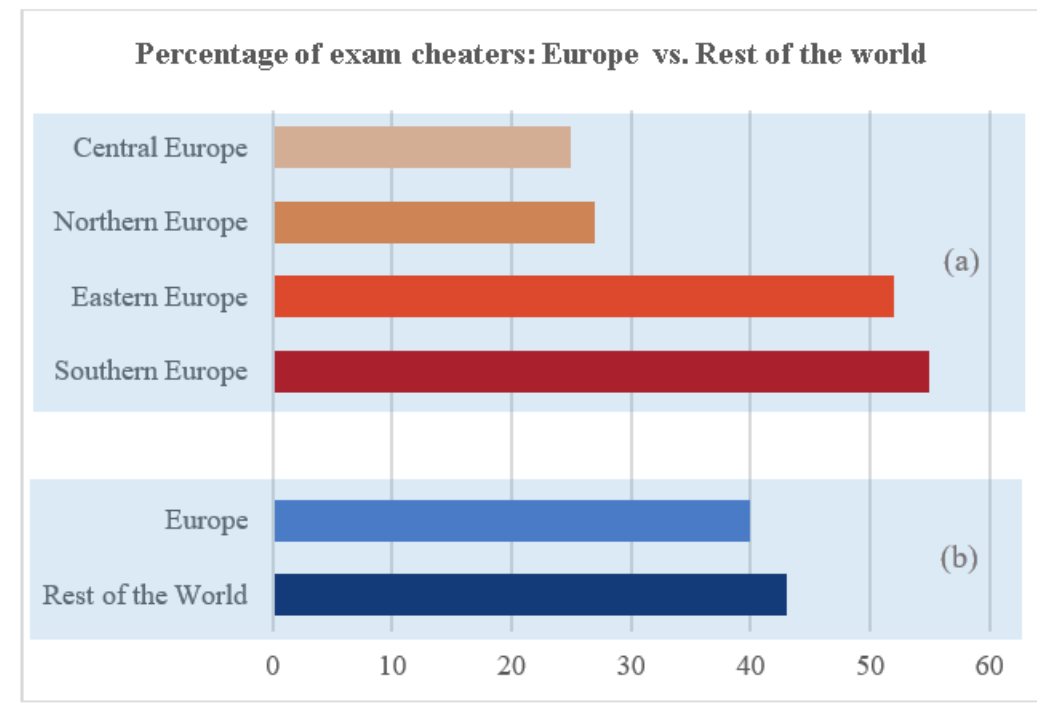

Notes: (a) Data collected from Europe. (b) Data collected from countries outside Europe.

Source: own processing, based on (Bucciol et al., 2020; McCabe, 2016; ICAI, 2015; Miller et al., 2014)

Figure 2 Graphic representation of exam cheaters data, across Europe and vs. Rest of the World. 
As for renowned higher institutions, there's a widespread belief that they have more diligence to counter cheating behaviour. However, there are some figures that prove otherwise. The research conducted by McCabe (2016), mainly based on data collected from 31 most competitive colleges in the U.S., pointed out that careful exam proctoring and honour codes reduce cheating rates, even though the concern persist. For instance, Harvard University has published information about 125 allegations of exam cheating back in 2012. In 2019, Yale reported that $14 \%$ from 1400 students involved in a survey confessed having cheated in exams, $24 \%$ admitted copying answers from classmates, while $26 \%$ spotted others cheat. As for Stanford, exam cheating incidents are reported every year, especially since the huge scandal back in 2012, when an investigation on a large number of students enrolled in a course took place and it was revealed that one in five (120 students) were breaking the honour code.

The high pressure at which students are exposed to get good grades and be intensely involved in extracurricular activities pushed them to bend the rules, but after all, what matters the most as a trigger for cheating is students' culture and personal problems (McCabe, 2016). Where clear rules regarding integrity does not exist, and where there is a lack of enforcement and penalties, cheating behaviour is blooming (Finchilescu et al., 2018; Peled et al., 2019). In this regard, developing and implementing an honour code, which is supported by all faculty members and clearly explained to students, are important steps in any university (Arnold et al., 2007; Burrus et al., 2007; Siev et al., 2019; Tatum et al., 2017).

Anyway, all the studies on the topic of cheating in exams suggests the existence of this widespread phenomenon across all universities and countries, and therefore the need for it to be mitigated.

\section{METHODOLOGY}

\subsection{Premises}

The analysis was conducted in the Faculty of Economics and Business Administrations (henceforth FEAA), which is one of the largest among the 15 faculties of Alexandru loan Cuza University of lasi, Romania, in terms of the number of enrolled students. In order to maintain its identity and be up to date with the latest trends and today's learners needs, the faculty's strategy for delivering online knowledge implies using Moodle as a Learning Management System (LMS). Continuing the experience of using Blackboard (former faculty's LMS) from 2009-2017, Moodle has been implemented in FEAA since 2018 as an alternative solution for face-to-face activities, and it has been used especially for the examination process. This process means conducting midterm and final exams, consisting in online quizzes that mainly contain multiple choice questions, true and false questions and short answer questions. This implies time-consuming and resource-intensive work on the part of teachers. The online quizzes that contain essay questions or other types of questions that require creative answers are few and are mainly addressed to the students enrolled at master's level. Due to the coronavirus pandemic and the shift to conducting educational activities online only, its use, along with other applications such as Microsoft Teams and the faculty portal, has become crucial. When it comes to fully online assessment, Moodle, which is strongly supported by a global community of developers, is highly-flexible, feature-rich, configurable, and more open to be used on all types of mobile devices than the previous LMS.

Proficiency in the use of digital technologies tempts some students to apply their knowledge for cheating on the exams. Although cheating on exams is wrong, there is a bright side to that. After all, juggling with questions and answers is essentially the same as taking notes, and once you've have them, you're already more than halfway there. Moreover, to ace all quiz answers implies a lot of concentration and creativity that is often more useful to students than the actual subject they are cheating in. And while academic honesty is good, it is not hard to see why students cheat. Many of them feel overwhelmed by the sheer amount of class-activities. They also 
feel as though they don't have the right resources to help them study in a 'self-pace' way. With a school day that starts at the crack of dawn and ends after several hours of online activities and practical-applications, it is not entirely difficult to understand why some students cheat.

In case of online quizzes, even if you opt-in for cheating-prevention tools such as online test-proctoring services (e.g. Examity, Proctorio) (Das, 2021), or for the adoption of punitive approaches such as time limits or shuffling the questions, the reality is that the students - worried about exam anxiety (Chin, 2020) - will always find out and came up with new and creative ways to get around all policing endeavours.

With the use of modern technologies, the traditional methods of cheating such as crib sheets, writing on the hand, submitting another classmate's test, collaborating in a group, and whispering the answers to questions have been left far behind. Nowadays, the students invent and create cheating methods that are easier and simpler than ever, some of which are, proven to be unbeatable (Gino et al., 2012).

Based on these existing premises the main objectives of the study are: (a) to conduct an analysis of cheating methods used by students when quizzing in Moodle and (b) to identify the counter-measures to these cheat scenarios, given as suggestions and recommendations which could be applied.

\subsection{Data sample and method}

At the time of data collection (April, 2021, in the $2^{\text {nd }}$ semester of study), FEAA has 7976 active students (at bachelor's, master's and doctoral level) and 297 on-duty teachers (of whom 132 are full professors and 165 are associate teaching staff).

To gather the necessary data, the methods used in the study are:

- A structured questionnaire, consisting of 'open-ended response' questions, as shown in Figure 3, and disseminated through the in-person interview method, among FEAA teachers.

- Qualitative methods consisting in observing the entire cheating process when quizzing: resolving of various mock requests made by students and receiving alarming notifications from teachers, tracking the similarity of quiz grades, users' logs, and their activity on Moodle.

After it was designed, the questionnaire was pre-tested and piloted during January 2021 exams session, on 6 respondents chosen randomly from among faculty teachers. The final sample is made up of 124 respondents out of a total of 297 teachers. We focused the questionnaire on teachers because students would have been tempted not to admit, not to disclose information, or to lie about the subject in question.

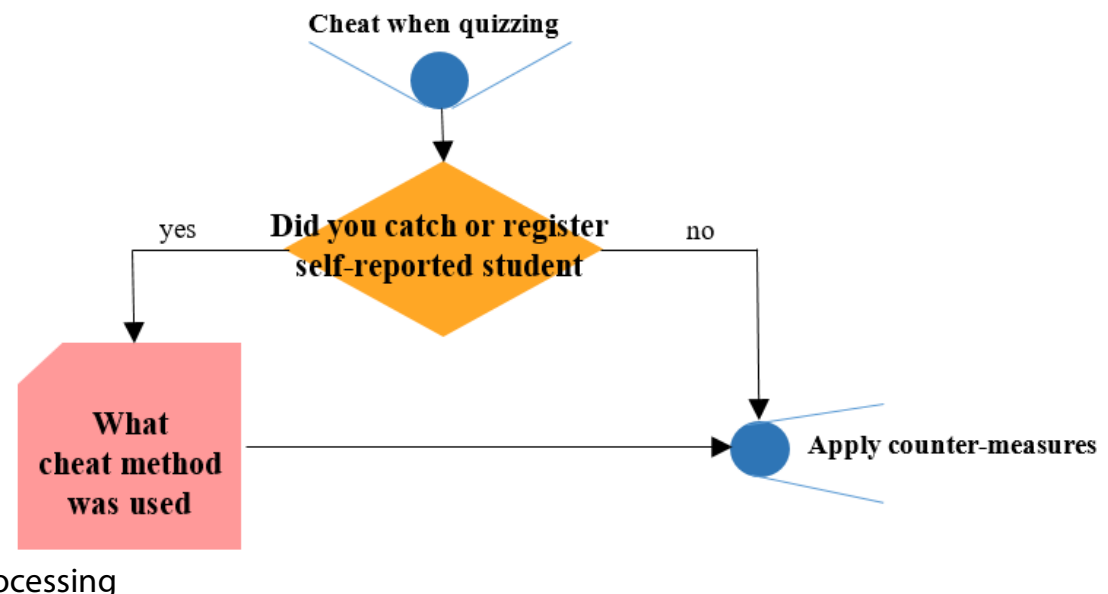

Source: own processing

Figure 3 The structure of the questionnaire used in collecting data about cheating in online quizzes

The analysis and synthesis of data were performed using MS Excel. 


\subsection{Study limits}

This study has certain limits related to the way of setting up the sample (only teachers in the field of economics and business administration were included, from just one university), to the way of conducting the interview (face-to-face) and to the way of designing the questionnaire ('openended response` questions only).

\section{RESULTS AND DISCUSSIONS}

Out of a total of 297 teachers of FEAA, 124 (41.8\%) were interviewed as a sample, with a focus on collecting data about quiz-cheating on Moodle during the 2020-2021 midterm and final exams in the field of economics and business administration. The teachers in the sample carry out 160 courses online (each involving two or even three online exams) at bachelor's and master's level, which cover a total number of 5,580 students. One should take into account, as a particularity and also as an influencing factor for cheating behavior, that the student cohorts are less numerous for the master's level (up to 80) than those for the bachelor's level (up to 230). Therefore, the most exposed exams to cheating are those for a large number of students (1st and 2nd year of study, bachelor's level), and also containing multiple-choice questions (the most frequent ones). Figure 4).

Other useful descriptive data about the respondents are shown in the following figure (see
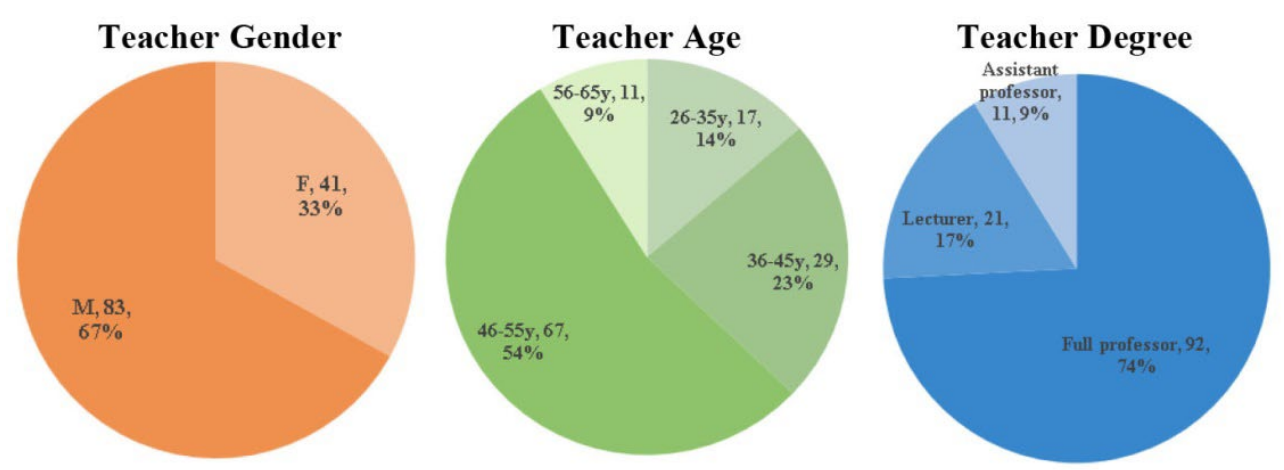

Source: own processing

Figure 4 Overview of descriptive data about sample

With regard to the interest shown in ensuring the efficiency, reliability and security of the online examination process, 108 respondents declare a high-interest (87.1\%), while just 16 of them declare a low-interest (12.9\%). The figures shows higher interest among male teachers (who are more tech-savvy and eager to control) than among female teachers. Regarding their involvement in the entire learning process - planning, teaching, assessing, full professors are the keenest on prevention, detection and countering of exam cheating, mainly because they think that the integrity of their courses over time is crucial.

By following the structure of the questionnaire step by step, the teachers had the possibility to list and describe their main issues regarding cheating behavior among students taking the online quizzes. On the other hand, this method enabled us to perform a qualitative assessment of the respondents' opinions and suggesstions. The results of processing the data collected has lead to the identification of the commonly used methods in Moodle quizzes, as shown in Table 1. The identification of cheating students was possible by matching the Moodle user ID with the faculty student ID. 
Table 1 Commonly used cheating methods in Moodle quizzes

\begin{tabular}{|c|c|c|c|}
\hline Method used & Method description and practices & Freq. & Rank \\
\hline $\begin{array}{l}\text { Exchange of } \\
\text { information between } \\
\text { classmates, through } \\
\text { collaborative group }\end{array}$ & $\begin{array}{l}\text { - Some students form up a group, by getting together in the same room, just for } \\
\text { collaborating (debating possible answers) while taking the quiz. A third party } \\
\text { (maybe more knowledgeable on the exam topic)could take part of this group. }\end{array}$ & 98 & 4 \\
\hline \multirow{3}{*}{$\begin{array}{l}\text { Exchange of } \\
\text { information between } \\
\text { classmates, through } \\
\text { online communication }\end{array}$} & - Private or group messages: inside Moodle, on Social Media platforms. & 120 & 2 \\
\hline & $\begin{array}{l}\text { - By using high-tech undetectable devices: such as tiny Bluetooth earbuds, } \\
\text { invisible smartwatches, augmented reality glasses, and other wearables that } \\
\text { might serve on the purpose. }\end{array}$ & 22 & 10 \\
\hline & $\begin{array}{l}\text { - Screen sharing/mirroring to a classmates: using software such as Team Viewer or } \\
\text { AnyDesk. }\end{array}$ & 119 & 3 \\
\hline \multirow{6}{*}{$\begin{array}{l}\text { Use of unallowed } \\
\text { resources and } \\
\text { materials }\end{array}$} & - By searching for answers online: Google, Quizlet, Brainy, blogs, forums. & 124 & 1 \\
\hline & $\begin{array}{l}\text { - By using education apps (such as Cymath or Brainly) that can help to get the } \\
\text { automated (or real-person) recommended answers instantly. }\end{array}$ & 21 & 11 \\
\hline & $\begin{array}{l}\text { - By using Virtual Machine software (such as VirtualBox) or 'virtual' webcam (such } \\
\text { as ManyCam). }\end{array}$ & 16 & 12 \\
\hline & - By using a friend, recruited to take the test on behalf of the student. & 40 & 6 \\
\hline & - By using a smaller laptop placed on the main laptop (to fool the webcam). & 11 & 13 \\
\hline & $\begin{array}{l}\text { - By hacking answers: students highlight or copy/paste the multiple-choice answers, then } \\
\text { run them through an online/local coding software that will detect and mark out them in } \\
\text { terms of codes ( } 1 \text { and } 0 \text { for the correct ones); after that, they return to the quiz webpage } \\
\text { and make the selection. (This requires technical know-how). }\end{array}$ & 28 & 9 \\
\hline \multirow{3}{*}{$\begin{array}{l}\text { Finding out the } \\
\text { content of the quiz }\end{array}$} & $\begin{array}{l}\text { - By using a mock student who can attempt the quiz just in order to see the } \\
\text { questions, and afterwards sharing them with classmates. }\end{array}$ & 34 & 8 \\
\hline & $\begin{array}{l}\text { - By using a mock attempt of the quiz, followed by addressing false excuses to the } \\
\text { examinator (such as 'Lost connection', 'Power outage') in order to obtain the } \\
\text { chance to another attempt. }\end{array}$ & 82 & 5 \\
\hline & $\begin{array}{l}\text { - By getting in contact with the previous takers of the test (from past promotion or } \\
\text { attempts). }\end{array}$ & 39 & 7 \\
\hline
\end{tabular}

Source: own processing, based on data collected from sample

To counter all possible cheating scenarios when online quizzing, comprehensive measures must be taken both by the faculty staff as well as by teachers (see Figure 5 ). With a bit of creativity and using good strategy, there are a few ways that examiners can make use of the features inside Moodle, whose quiz engine is flexible, yet powerful. Let us explore them, at a glance:

- Restrict quizzing window. Set time limits, according to the difficulty of the quiz. Give enough time for students who knows the topic, but not too much, so they cannot do the searching. Customize timings for students who gained approval to trial the quiz environment.

- Random and shuffle the questions and the answer options. Store and classify questions in categories, from where they could be extracted randomly for each attempt, and also shuffle the display of the answer options. Try to maximize the number of questions from a question bank, and also allow one quiz attempt only.

- Mix up several question types. Creating quizzes with multiple choice, true and false, and open-ended response questions, will push students to be more creative and write unique responses. In case of open-ended questions, use those that require students to be creative and demonstrate their knowledge.

- Set up a practice quiz. A zero point quiz with few questions similar to the real one will ensure students to adjust to the environment and to the topic, and also will reduce anxiety. 
Let the quiz be taken as many times as they like, and display only feedbacks. Also, this could be a good strategy for eventually 'technical issues'.

- Set the quiz to show one question per screen and to prohibit backtracking. This settings requires students to better focus on questions and force them to give their best answers.

- Activate Safe Exam Browser or set 'Full screen pop-up'. By using an open-source lock-down browser, downloading or printing the questions cannot be done at all. Alternatively, the quiz could appears in a pop-up window that covers all other apps windows, and keep the student 'freezed' until submitting the test. To mention that these settings add the hurdles that students have to install additional softwares on their devices.

- Set password as an extra restriction on attempts.

- Prohibit messaging inside Moodle.

- Combine assessment methods. Teachers could take into account giving less weight to quizzes, then mix them up with assignments and projects, which are more creative and require originality.

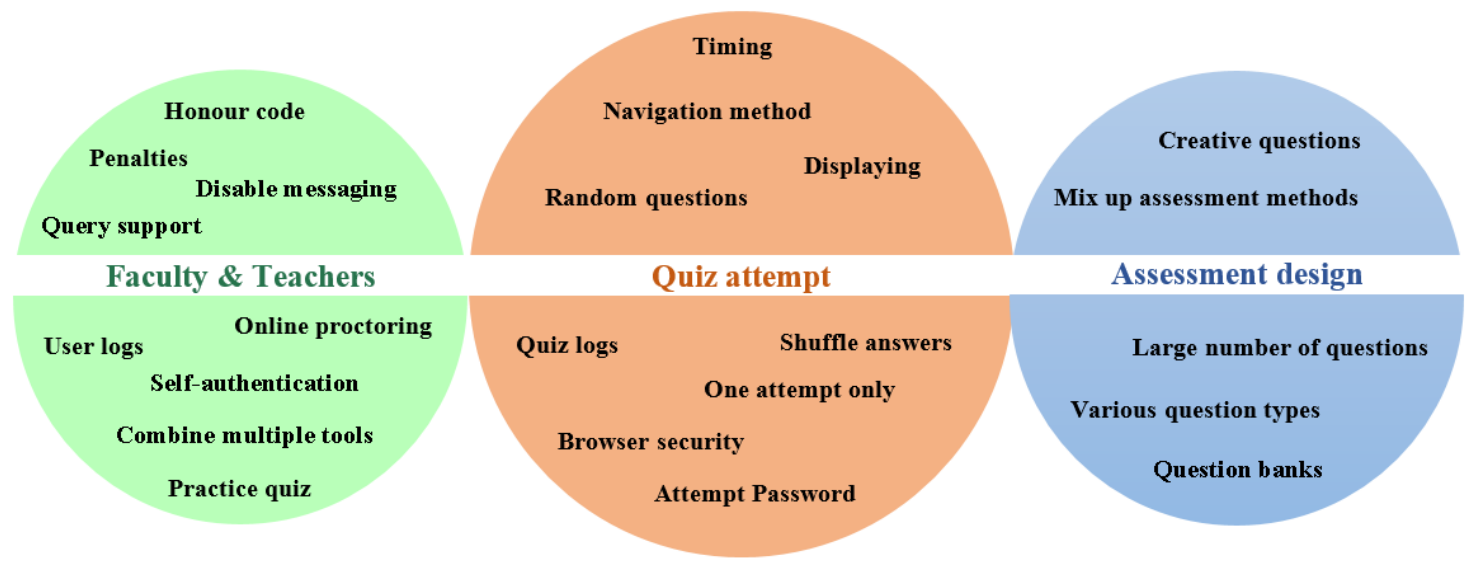

Source: own processing

Figure 5 Overview of countermeasures to cheating on quizzes

Also, we emphasise a couple of measures outside Moodle:

- Instate faculty's honour code. Ask students to acknowledge having read the rules or even require them to sign an academic integrity contract prior to taking the quiz (using polling or survey features within Moodle). Placing statements (and a link to the faculty's academic integrity policy website) on the cover page or at the beginning of quizzes has been shown to reduce cheating among students (Siev et al., 2019; Tatum et al., 2017).

- Auto/Live online proctoring. Using proctoring software that record test-takers' head, keystroke, eye movements and also audio (voice) during the quiz, or observing students and chatting with them in real time are a 'next-level' move but may be expensive and considered as unreliable by teachers. As a minus for students, taking quizzes under the eye of a proctor may have a negative impact on getting good grades or mastering the course. (Lieberman, 2018).

- Set penalties and explain them to students. 
- Monitoring IP address during a quiz. The teacher could use a Moodle-plugin (or feature, such as quiz log) or additional software to identify the student's IP address (even pinpoint his remote location), and tracking down if someone else take the quiz from the same location.

- Self-authentication. Facial features, fingerprints and identity cards can be used to prevent impersonation, but this requires a complex technology, training, and also raises some concerns about data security and privacy.

- Query support. Ensure that students do not face technical or functional issues before, during or after an online exam. In case of queries or requests, these should be resolved as soon as possible by the teacher.

- Handle online exam with the help of other tools, such as Microsoft Teams, Zoom, Google Meet, and so on, or mix them up with Moodle.

The students should keep in mind that cheating attempts during quizzes can affect more or less their grades as well as lead to more serious penalties such as suspension from studies.

\section{CONCLUSIONS}

Although many cheaters tend to view cheating as a victimless crime or a 'no big deal phenomenon', this problem leads to undesirable consequences for both students and the educational system. Especially during this period of uncertainty caused by the coronavirus pandemic, it remains a concern for the higher education institutions, pushed to move almost completely online. Academic integrity is much more than avoiding dishonest practices such as cheating on quizzes or plagiarizing. It implies focusing on doing things in a proper manner, good skills, individual effort and engagement in the entire process of learning.

As a result of turning learning into e-learning, all of the teachers are not only expected to have a complete understanding of their topics, but they are also required to be - at least partially skilled in new ways of teaching ((Chikasanda et al., 2013; Tschida et al., 2016), and particularly in online quizz designing (Romeu Fontanillas et al., 2016). Therefore, this big shift affects the beliefs, experiences and roles of the teachers (Coppola et al., 2001; McQuiggan, 2007; Redmond, 2011), and challenges them to face important (even difficult, for some) transformations in order to gain new tech skills (Boon, 2015; Salmon, 2011). We could speak out about a new species: 'tech savvy teacher'.

On the other hand, prevention, detection and countering of exam cheating is like a task because accreditation groups (moved by government regulators) demand that faculties (and examiners) 'do something' to verify the identity of online students, and take action on all possible levels: technological, institutional and psychological.

When it comes to online exams, the present study identified some limitations to take into consideration:

- Technical failure. If something goes out of control (lost connection, device crashes or power outage), there is no backup for taking the exam in an alternate way.

- Anxiety and stress. Using proctoring could enhance anxiety among overwhelmed students.

- Privilege issues. Students may not have the right permissions (or don't know how) to install some required software on their devices.

When it comes to interpreting the results, the study also presents some limitations that should be considered:

- Study domain. The results suggest that cheating on exams among economics students is frequent enough to draw special attention on the matter. We intend to continue the 
research by performing a cross-domain analysis in which to include a higher number of faculties and even universities..

- Only cheating on one type of online exam was analysed - the quiz. Despite being the most widely used online exam method when dealing with a large number of students, it would be interesting to analyse the cheating scenarios (namely plagiarism) on other types of assessments, such as the case of essays, assignments and individual or group projects.

The current study shows the ongoing concerns on discouraging fraudulent attempts on exams, as a consequence of conducting them fully online (especially within today's context). As the study results shows, the cheating methods identified are numerous and permanently developing. Nonetheless, from now on, almost all the assessments should be monitored using remote proctoring softwares and Artificial Intelligence-powered algorithms. The main goal here is to aid faculties to conduct online exams in a cheating-free environment. This will be not only a real challenge, but also a great opportunity for stakeholders to completely open up and adapt to the fact that fully online learning became the new normal in education.

\section{REFERENCES}

Arnold, I.J.M. (2016). Cheating at online formative tests: Does it pay off?, Internet and Higher Education, 29, 98-106. https://doi.org/10.1016/j.iheduc.2016.02.001

Boon, B. (2015). Active Online Teaching Strategies-Sharing Best Practices, Proceedings of the 2nd Lilly Conference college and university teaching and learning - in Austin, Texas.

Brown, B.S. (2000). The academic ethics of the graduate business students: 1993 to 1998, Journal of Applied Business Research, 16, 1005-112. https://doi.org/10.19030/jabr.v16i4.2058

Bucciol, A., Cicognani, S., Montinari, N. (2020). Cheating in university exams: the relevance of social factors. International Review of Economics, 67, 319-338. https://doi.org/10.1007/s12232-019-00343-8

Burrus, R.T., McGoldrick, K., Schuhmann, P.W. (2007). Self-reports of student cheating: Does a definition of cheating matter?, Journal of Economic Education, 38(1), 3-16. https://doi.org/10.3200/JECE.38.1.3-17

Chikasanda, V.K., Otrel-Cass, K., Williams, J., Jones, A. (2013). Enhancing teachers' technological pedagogical knowledge and practices: A professional development model for technology teachers in Malawi. International Journal of Technology and Design Education, 23(3), 597-622. https://doi.org/10.1007/s10798-012-9206-8

Choi, C. (2009). The pull of integrity, ASEE Prism, Washington, 18(7), 29-33. https://doi.org/10.1111/an.1992.33.7.29

Coppola, N.W., Hiltz, S.R., Rotter, N. (2001). Becoming a virtual professor: Pedagogical roles and ALN. Proceedings of the 34th Hawaii International Conference on System Sciences, Maui: Institute of Electrical and Electronics Engineers, 1-10. https://doi.org/10.1109/HICSS.2001.926183

Gino, F., Ariely, D. (2012). The dark side of creativity: Original thinkers can be more dishonest. Journal of Personality and Social Psychology, 102(3), 445-459. https://doi.org/10.1037/a0026406

Ellis, D.B., Dawson, D., Toft, D. (2020). Becoming a master student, Cengage Learning, Toronto.

Englander, F., Fask, A., Wang, Z. (2011). Comment on 'The impact of online assessment on grades in community college distance education mathematics courses' by Ronald W. Yates and Brian Beaudrie, The American Journal of Distance Education, 25, 114-120. https://doi.org/10.1080/08923647.2011.565243

Finchilescu, G., Cooper, A. (2018). Perceptions of Academic Dishonesty in a South African University: A QMethodology Approach, Ethics \& Behavior, 28(4), 284-301. https://doi.org/10.1080/10508422.2017.1279972

McCabe, D.L. (2016). Cheating and Honour: Lessons from a Long-Term Research Project. Handbook of Academic Integrity. Bretag T. (eds) Handbook of Academic Integrity, (1st), Springer, Singapore, 187-198. https://doi.org/10.1007/978-981-287-098-8_35

McCabe, D.L., Butterfield, K.D., Trevino, L.K. (2006). Academic Dishonesty in Graduate Business Programs: Prevalence, Causes, and Proposed Action, Academy of Management Learning \& Education, 5(3), $294-305$. https://doi.org/10.5465/amle.2006.22697018

McCabe, D.L., Trevino, L.K. (2017). Academic dishonesty: Honour codes and other contextual influences, Academic Ethics, Taylor and Francis, 545-562. https://doi.org/10.4324/9781315263465-43 
McGuire, S.Y. (2015). Teach students how to learn: Strategies you can incorporate into any course to improve student metacognition, study skills, and motivation, ProQuest Ebook Central.

Miller, B.L., Chavez, L.A., Posick, C., Gould, L.A. (2014). Cheating Around the World: A Cross-national Analysis of Principal Reported Cheating. Journal of Criminal Justice Education. 26(2). https://doi.org/10.1080/ 10511253.2014 .986148

Nilson, L.B. (2013). Creating Self-regulated Learners: Strategies to Strengthen Students' Self-awareness and Learning Skills. 1st ed., Sterling, Virginia: Stylus Publishing.

Orosz, G., Toth-Kiraly, I., Bothe, B., Paskuj, B., Berkics, M., Fulop, M., Roland-Levy, C. (2018). Linking cheating in school and corruption, Revue Européenne de Psychologie Appliquée, 68(2), 89-97. https://doi.org/10.1016/j.erap.2018.02.001

Peled, Y., Eshet, Y., Barczyk, C., Grinautski, K. (2019). Predictors of Academic Dishonesty among undergraduate students in online and face-to-face courses. Computers \& Education, 131(1), Elsevier Ltd., $49-59$. https://doi.org/10.1016/j.compedu.2018.05.012

Redmond, P. (2011). From face-to-face teaching to online teaching: Pedagogical transitions. In G. Williams, P. Statham, N. Brown, \& B. Cleland (Eds.), Changing demands, changing directions. Proceedings of the ascilite conference, Hobart (Tasmania), 1050-1060.

Romeu Fontanillas, T., Romero Carbonell, M., Guitert Catasús, M. (2016). E-assessment process: giving a voice to online learners, International Journal of Educational Technology in Higher Education, 13(1), 1-14. https://doi.org/10.1186/s41239-016-0019-9

Salmon, G. (2011). E-moderating: The key to teaching and learning online. (3rd), New York: Routledge.

Stephens, J.M. (2016). Creating cultures of integrity: a multilevel intervention model for promoting academic honesty. In Bretag $T$ (ed) Handbook of academic integrity, (1st), Springer, Singapore, 995-1008. https://doi.org/10.1007/978-981-287-098-8_13

Tatum, H., Schwartz, B.M. (2017). Honour codes: Evidence based strategies for improving academic integrity, Theory Into Practice, 56(2), 129-135. https://doi.org/10.1080/00405841.2017.1308175

Teixeira, A.A.C., Rocha, M.F. (2010). Cheating by economics and business undergraduate students: An exploratory international assessment, Higher Education, 59(6), 663-701. https://doi.org/10.1007/s10734-009-9274-1

Tschida, C., Hodge, E., Schmidt, S. (2016). Learning to teach online: Negotiating issues of platform, pedagogy and professional development. In V. Wang (Ed.), Handbook of research on learning outcomes and opportunities in the digital age, Hershey, PA: Information Science Reference, 664-684. https://doi.org/10.4018/978-1-4666-9577-1.ch029

Internet resource

Baran, L., Jonason, P.K. (2020). Academic dishonesty among university students: The roles of the psychopathy, motivation, and self-efficacy, PLOS ONE Journal, 15(8), https://doi.org/10.1371/journal.pone. 0238141, [accessed 24.04.2021]. https://doi.org/10.1371/journal.pone.0238141

Chin, M. (2020). Exam anxiety: How remote test-proctoring is creeping students out, The Verge, https://www.theverge.com/2020/4/29/21232777/examity-remote-test-proctoring-online-class-education, [accessed 19.04.2021].

Das. J. (2021). Best Online Exam and Assessment Proctoring Software to Look Up, https://www.software suggest.com/blog/best-online-exam-proctoring-software/\#, [accessed 22.04.2021]

Lieberman, M. (2018). Exam Proctoring for Online Students Hasn't Yet Transformed, Inside Higher Ed., https://www.insidehighered.com/digital-learning/article/2018/10/10/online-students-experience-wide-rangeproctoring-situations-tech, [accessed 23.04.2021].

McQuiggan, C.A. (2007). The role of faculty development in online teaching's potential to question teaching beliefs and assumptions, Online Journal of Distance Learning Administration, http://www.westga. edu/ distance/ojdla/fall103/mcquiggan103.htm, [accessed 23.04.2021].

Romeu Fontanillas, T., Romero Carbonell, M., Guitert Catasús, M. (2016). E-assessment process: giving a voice to online learners, International Journal of Educational Technology in Higher Education, 13, https://doi.org/ 10.1186/s41239-016-0019-9, [accessed 22.04.2021]. https://doi.org/10.1186/s41239-016-0019-9

Siev, S., Kliger, D. (2019). Cheating in academic exams: A field study. In Dishonesty in Behavioral Economics (111-140), Academic Press, https://doi.org/10.1016/B978-0-12-815857-9.00008-X, [accessed 16.04.2021]. https://doi.org/10.1016/B978-0-12-815857-9.00008-X 
The International Center for Academic Integrity (ICAI). (2015). Report on Cheating on Tests, https://www.aca demicintegrity.org/statistics/, [accessed 14.04.2021].

UNESCO. (2021). Report on Global Monitoring of School Closures, https://en.unesco.org/covid19/ educationresponse, [accessed 6.04.2021].

https://quizlet.com/features/how-quizlet-works, [accessed 26.04.2021].

https://brainly.in/teachers-and-schools, [accessed 26.04.2021].

https://manycam.com/education/, [accessed 26.04.2021]. 